\title{
Phytopathology
}

\section{Phenomic Approaches and Tools for Phytopathologists}

\author{
Ivan Simko, Jose A. Jimenez-Berni, and Xavier R. R. Sirault
}

First author: U.S. Department of Agriculture, Agricultural Research Service, U.S. Agricultural Research Station, 1636 E. Alisal St., Salinas, CA 93905; and second and third authors: CSIRO Agriculture and Food, High Resolution Plant Phenomics Centre, Australian Plant Phenomics

Facility, GPO Box 1600, Canberra, ACT 2601, Australia.

Accepted for publication 3 September 2016.

\begin{abstract}
Plant phenomics approaches aim to measure traits such as growth, performance, and composition of plants using a suite of noninvasive technologies. The goal is to link phenotypic traits to the genetic information for particular genotypes, thus creating the bridge between the phenome and genome. Application of sensing technologies for detecting specific phenotypic reactions occurring during plant-pathogen interaction offers new opportunities for elucidating the physiological mechanisms that link pathogen infection and disease symptoms in the host, and also provides a faster approach in the selection of genetic material that is resistant to specific pathogens or strains. Appropriate phenomics methods and tools may also allow presymptomatic detection of disease-related changes in plants or to identify changes that are not visually apparent. This review focuses on the use of sensor-based phenomics tools in plant pathology such as those related to digital imaging, chlorophyll fluorescence imaging, spectral imaging, and thermal imaging. A brief introduction is provided for less used approaches like magnetic resonance, soft x-ray imaging, ultrasound, and detection of volatile compounds. We hope that this concise review will stimulate further development and use of tools for automatic, nondestructive, and high-throughput phenotyping of plant-pathogen interaction.
\end{abstract}

Plant diseases cause economically important loss of yield and quality of agricultural production worldwide, thus affecting food safety and security. New cultivars with resistance to devastating diseases would reduce economic losses in the areas under disease pressure while limiting extensive use of chemicals. Development of new cultivars with high levels of resistance usually requires extensive phenotypic evaluations of germplasm, hybrids, and breeding lines that are labor intensive, expensive, and time consuming. While genotyping with DNA-based molecular markers is routinely performed in breeding programs (Anderson et al. 2001; Simko 2013; Young 1996), sensor-based, automated or semi-automated phenotyping is still only in the early stages of development, thus creating a bottleneck in the plant evaluation process (Furbank and Tester 2011). Therefore, there is the need for the development of highquality, high-throughput, disease-sensing, phenotyping tools that will allow more rapid development of new cultivars with improved disease resistance.

Phenomics tools can also be used for dissecting the mechanisms of plant-pathogen interactions and elucidating the functional aspects of plant susceptibility to the disease. For example, accurate phenotyping may identify plant architecture that creates conditions

Corresponding author: I. Simko E-mail address: Ivan.Simko@ars.usda.gov

This article is in the public domain and not copyrightable. It may be freely reprinted with customary crediting of the source. The American Phytopathological Society, 2017. favorable for a particular disease (e.g., influence of the canopy aerodynamics on creating water pockets). Phenomics combined with modeling are the right tools for understanding these functional aspects. Besides evaluating plants, phenomic-related tools are important for measuring environment factors, such as temperature and humidity that provide additional information about plant performance. Using such a multifaceted approach is important when discriminating between biotic and abiotic stress. For instance, many disease symptoms resemble those related to water stress. Having information about environmental factors allows for more accurate diagnosis of the disease; e.g., information about sufficient soil water content may rule out possible water stress. Combining different phenomics techniques that better explain the etiology of the disease also helps in identifying the actual disease.

Assessments of plant-pathogen interactions, such as hypersensitive response (HR), or disease progress are frequently performed visually. However, visual assessments may be inaccurate and/or imprecise with non-constant error rate at different levels of infections (Bock et al. 2010). Evaluations performed with phenotyping tools may minimize or eliminate subjectivity associated with sensory assessments. In addition, sensor-based phenotyping could be amenable to automation, thus allowing for more rapid evaluations, reducing the cost of labor, and permitting more frequent measurements of the same plants over time. If appropriate methods and tools are selected, phenomics may also detect disease-related changes in plants before they are visually observed (presymptomatic detection), or identify changes not visually apparent. Such early and 
accurate assessments of plant reactions are important factors when investigating plant-pathogen interaction, the development of new cultivars in breeding programs, and ultimately in the management of crops where these techniques could be applied at a large scale in an agronomic context.

Phenotyping can be performed on individual plants or a group of plants in a laboratory, growth chamber, greenhouse, or field (Araus and Cairns 2014; Fiorani and Schurr 2013). Using sensors for detection of plant disease has a long history (Hatfield and Pinter 1993; Jackson 1986; Taubenhaus et al. 1929), however with the advent of new technologies sensor-based phenotyping became to be more extensively used for detecting and quantifying crop stress caused by biotic and abiotic factors (Nilsson 1995a, b). Optical sensors, the most frequently used sensors for remote sensing, can be classified based on their type (imaging and nonimaging), spectral resolution, spatial resolution (Steiner et al. 2008), and source of radiation (passive and active) (Mahlein et al. 2012a). Passive sensor systems measure object's natural radiation or the reflectance of solar radiation while active systems are equipped with their own source of radiation. Active sensors are generally less affected by environmental factors (Mahlein et al. 2012a), but they may be limited in their speed of measurements (e.g., active chlorophyll fluorescence sensors). Nonimaging sensors average the reflectance over an entire sensor's field (Steiner et al. 2008) while the most advanced imaging sensors, such as hyperspectral cameras detect both the spectral and the spatial information about the object (Mahlein et al. 2012a).

Spectral resolution is the ability of the sensor to separate individual spectral bands, while spatial resolution of sensors (i.e., their ability to distinguish details) generally depends on a distance between the sensor and the object. Sensors far away from observed objects (e.g., those mounted on aircraft or space-based platforms) are typically not able to provide fine details and have a lower spatial resolution compared with the sensors analyzing objects from proximity. Remote sensors, however, can view larger areas and are suitable for analyses of whole fields or orchards, while proximal (near-range) remote sensors are fitting for more detailed analyses of individual plants or their parts.

A variety of sensor systems were successfully applied at the whole field, individual plant, or plant organ level to detect stress or damage caused by diseases or pests (Fahlgren et al. 2015; Goggin et al. 2015; Mahlein 2016; Mahlein et al. 2012a; Martinelli et al. 2015; Mutka and Bart 2014; Pridmore et al. 2012; Sankaran et al. 2010; Scholes and Rolfe 2009; White et al. 2012). In this review we focus primarily on advances in using sensor-based phenotyping in phytopathology since 2000 and future perspectives of applying phenomic tools for examining plant-pathogen interaction. Emphasized are the most frequently used sensing techniques, while succinct information is provided for less often used approaches. We hope that this assessment of available tools, technologies, and methods will stimulate further use of phenomics

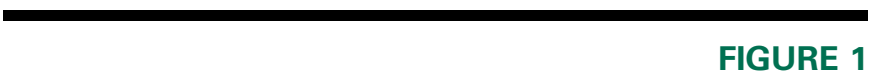

Spectrum of electromagnetic radiation. Multiple types of the radiation are used for nondestructive, sensor-based analyses of plant-pathogen interaction. approaches for evaluating plant-pathogen interactions and motivate development of improved and novel tools for automatic, nondestructive, high-throughput plant phenotyping.

\section{DIGITAL IMAGING IN VISIBLE ELECTROMAGNETIC SPECTRUM}

Typically, digital cameras are designed to emulate human vision by sensing light in the visible range of electromagnetic spectrum (wavelengths from about 390 to $700 \mathrm{~nm}$, Fig. 1). Devices working with these wavelengths are also called RGB devices because they use the red, green, and blue light color model to estimate the true color of each pixel (while the additive RGB color model is used by majority of digital cameras, subtractive CMYK color model based on combining cyan, magenta, and yellow is used by many color printers). The optical properties of plants are a complex phenomenon that depends on transmission of light through the plant tissue, absorption of light by plant chemicals (e.g., pigments, water, and sugars), and reflection of light by plant surface or internal structures (Mahlein 2016). Reflectance at the visible range of electromagnetic spectrum is predominantly influenced by plant pigments, while plant internal structures, water content, and chemical composition affect primarily reflectance in the range from 700 to $2,500 \mathrm{~nm}$ (Mahlein 2016).

Analysis of digital images on the microscopic, organ, plant, or field level is an important tool used in plant pathology. RGB-based sensors can readily detect changes on plants occurring due to pathogen infections such as appearance of pathogen structures (e.g., presence of hyphae) or reaction of plants to pathogens (e.g., degradation of tissue leading to chlorosis, necrosis, or changes in organ structure). The use of standard color cameras is very attractive because of the low cost and simple operation (Casadesús et al. 2007; Zhou et al. 2015). Standard digital images of plants can be processed by commonly available software (Bock et al. 2010) to measure a variety of traits such as disease progress or leaf damage. Digital phenotyping can reduce human subjectivity in trait quantification as was shown on the example of maize (Zea mays L.) leaves damaged by Southern leaf blight caused by the fungus Cochliobolus heterostrophus (Drechsler) (Green et al. 2012). This nondestructive analysis can be performed with freely available, web-based software on images taken in the laboratory, greenhouse, or field (Green et al. 2012).

Plant immune response triggered by filamentous pathogens can lead to deposition of callose (Zhou et al. 2012). Measuring deposition of callose on microscopic digital images allows for the detection of the growth of hyphae in leaves and for quantification of the plant immune reaction. Practical use of the method was demonstrated by analyzing differences in callose deposition between genotypes of Arabidopsis thaliana L. plants inoculated with the oomycete Hyaloperonospora arabidopsidis (Zhou et al. 2012).

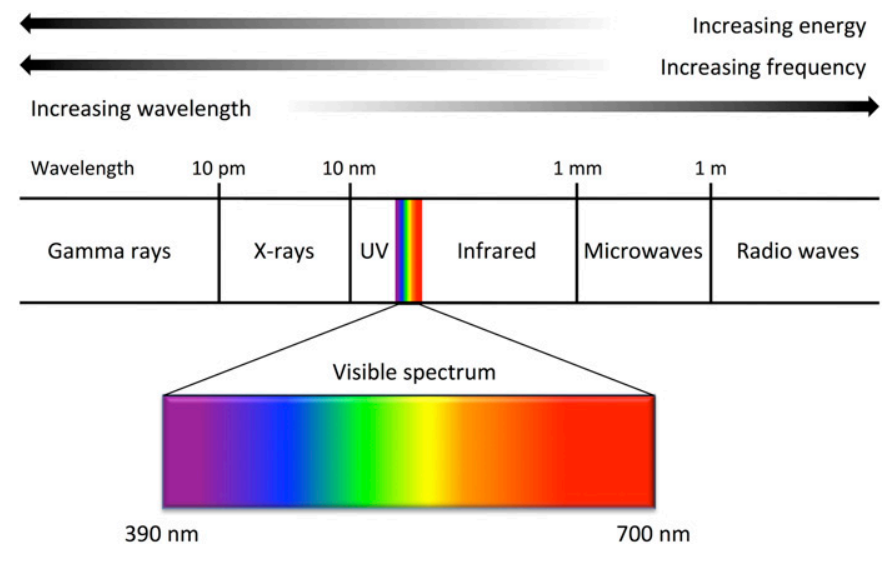


At the organ level, interaction between lettuce genotypes (Lactuca sativa L.) and powdery mildew caused by the fungus Golovinomyces cichoracearum sensu stricto was evaluated using digital imaging. The percentage of the leaf area covered by the disease was calculated from standard color photographs and analyzed using commercial software (Fig. 2). The results were used to detect quantitative trait loci for resistance to the disease (Simko et al. 2014). In some cases, however, using digital imaging system for evaluation of diseased areas may not work due to specific problems. For example, a problem with analysis of digital images was reported when three methods were compared for quantification of powdery mildew (Podosphaera clandestina (Wallr.:Fr.) Lev.) infection on sweet cherry (Prunus avium L.) leaves: visual assessment, digital image analysis, and the ground truth based on digital image analysis of enamel painted pathogen colonies that were detected using a dissecting microscope (Olmstead et al. 2001). Though a strong relationship was observed between visual assessments and the ground truth $\left(R^{2}=0.88\right.$ to 0.95$)$, a relatively weaker, yet highly significant relationship was observed between the ground truth and digital image analyses $\left(R^{2}=0.46\right.$ to 0.66$)$. The authors contributed these results to the inability of the image processing software to detect slight differences in color between healthy and diseased leaf tissue. Thus, it is likely that more recent software with improved color resolving ability (e.g., ImageJ 1.49k from National Institutes of Health, Bethesda, MD, or Assess 2.0 from The American Phytopathological Society, St. Paul, MN) would allow for more accurate detection of powdery mildew lesions.

A disadvantage of using cameras with sensors detecting visible light is their high sensitivity to a broad range of the electromagnetic spectrum. Thus, specific wavelength information may be lost in the output image (Fahlgren et al. 2015). Also, special attention needs to be paid to all steps related to image acquisition such as uniformity of illumination, focus, and sharpness. These are usually easy to attain in laboratory conditions but more difficult to achieve under constantly changing field conditions. Heterogeneous conditions may lead to an inferior image quality and subsequently to a low level of accuracy (Mahlein 2016). In addition, several authors have stressed problems caused by reflection (glare or specular reflectance), shadows, and angles and their effects on the accuracy of image analysis (reviewed in Bock et al. 2010).

\section{CHLOROPHYLL FLUORESCENCE IMAGING (CFI)}

Infections by some pathogens rapidly affect photosynthetic performance of plants. Changes in photosynthetic responses of infected tissue can be detected by methods based on CFI. CFI is a well-established, nondestructive method for investigating effects of pathogens on photosynthetic metabolism of host plants at the wholeplant, detached leaf, and leaf disks levels (Fig. 3). The analysis of chlorophyll fluorescence is based on the principle that energy of light absorbed by chlorophyll molecules is either used in photosynthesis, dissipated as heat, or re-emitted as chlorophyll fluorescence (Maxwell and Johnson 2000). Because these three processes happen in competition, chlorophyll fluorescence data provide information about the efficiency of photosynthesis and heat dissipation (photochemical and non-photochemical quenching). To assess chlorophyll fluorescence, the light of a defined wavelength is directed to a plant and the fluorescence signal (re-emitted light at longer wavelengths) is measured (Maxwell and Johnson 2000). Because an external source of light (LED or laser) is provided for such measuring systems, instruments based on CFI are classified as active sensors. Several parameters derived from measurements of chlorophyll fluorescence can be investigated in relationship with changes in photosynthesis occurring during plant-pathogen interaction (Rolfe and Scholes 2010; Scholes and Rolfe 2009): $F_{v} / F_{m}$ - maximum quantum efficiency of photosystem II (PSII), where $F_{m}$ is the maximum chlorophyll $a$ fluorescence yield in the dark-adapted state, $F_{v}$ is the maximum variable fluorescence in the dark-adapted state (calculated as $F_{m}-F_{o}$ ), and $F_{o}$ is the minimum chlorophyll $a$ fluorescence yield in

FIGURE 2

Automatic recognition of powdery mildew lesions on RGB image of lettuce leaf (left) and quantification of infected area from binary maps of four different leaves (right) (G. Rauscher and I. Simko, unpublished data).
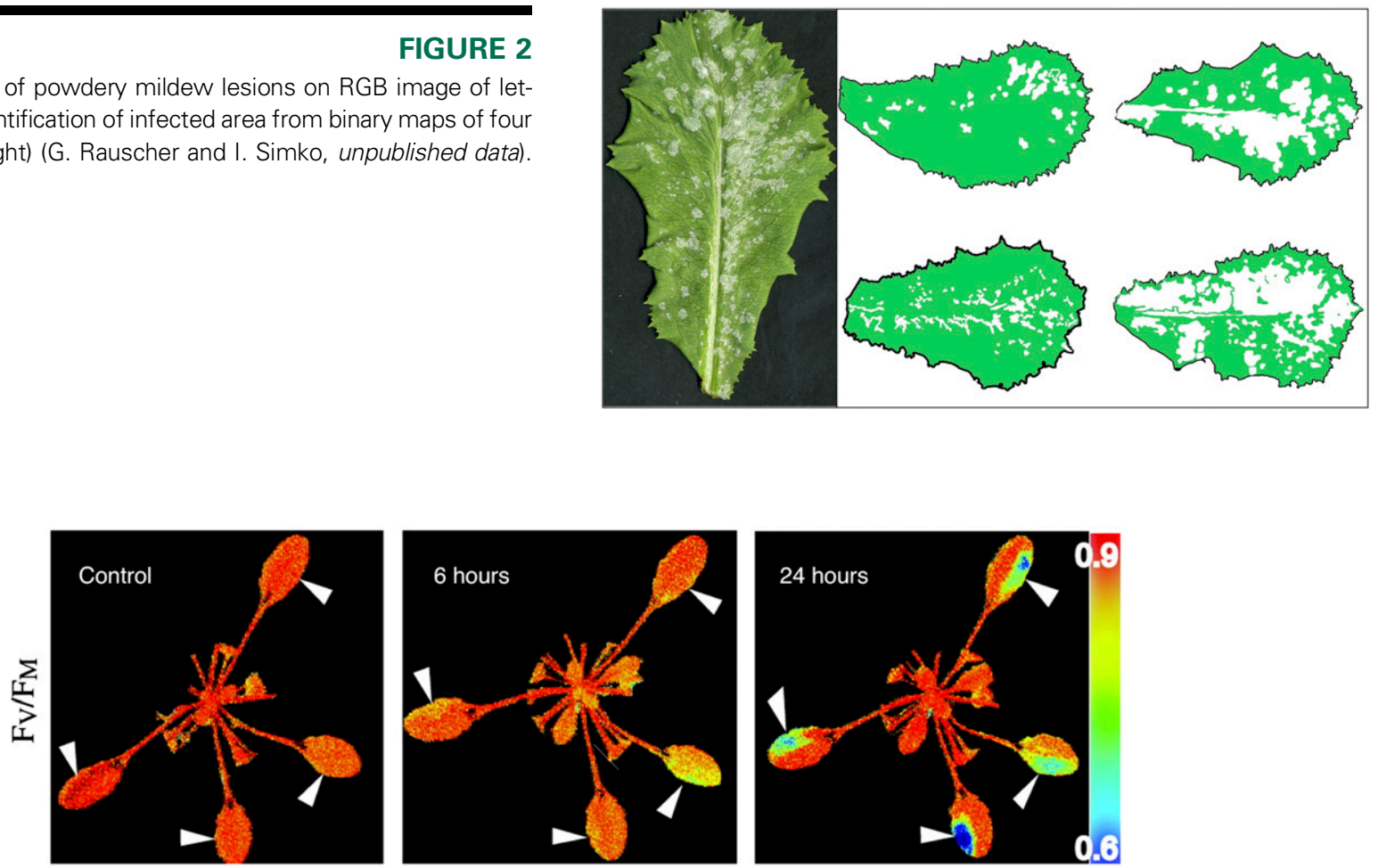

\section{FIGURE 3}

Chlorophyll fluorescence imaging $\left(F_{v} / F_{m}\right.$ parameter) of Arabidopsis thaliana plants inoculated with Pseudomonas syringae. A plant not inoculated with the pathogen is on the left; middle panel shows a false color image $6 \mathrm{~h}$ after inoculation; and the right panel shows results $24 \mathrm{~h}$ after inoculation. Inoculation sites are indicated with white arrows. The $F_{v} / F_{m}$ scale is on the right. Reproduced with permission from Berger et al. (2007). 
the dark-adapted state; $\Phi_{\mathrm{PSII}}$ is the operating efficiency of PSII; ETR is the linear electron transport rate through PSII; and NPQ is the nonphotochemical quenching. These parameters are frequently derived from evaluations performed after a period of dark adaptation that is needed to obtain a nonstressed reference point (Maxwell and Johnson 2000).

For example, the $F_{v} / F_{m}$ ratio has reliably distinguished maize cultivars with resistant and susceptible reaction to southern corn rust disease caused by Puccinia polysora (Durães et al. 2002). Results of the CFI indicate that the pathogen caused injury to thylakoid structure, thus affecting the photosynthetic electron transport (Durães et al. 2002). CFI was used for rapid detection of changes in the $F_{v} / F_{m}$ ratio on ears of winter wheat following inoculation with Fusarium culmorum (Bauriegel et al. 2011a, 2012). The $F_{v} / F_{m}$ ratio on damaged kernels dropped to zero 6 to 11 days after inoculation (DAI). CFI reliably recognized infected ears, and allowed differentiation between ears with a different severity of disease. Limitation of the method was seen at later plant growth stages when natural degradation of chlorophyll occurs due to ripening of kernels (Bauriegel et al. 2011a, 2012). CFI rapidly and objectively classified reactions of lettuce (Lactuca sativa L.) cultivars to Bremia lactucae Regel., the oomycete causing downy mildew disease (Bauriegel et al. 2014). The patchy distribution of $F_{v} / F_{m}$ revealed the dynamics of disease progress on lettuce leaf discs infected with the pathogen. Further, the method was able to distinguish between different types of infections; the one caused by B. lactucae and a secondary contamination of leaf tissue caused by species of fungi from genera Alternaria, Penicillium, and Cladosporium, observed when leaf discs were cultivated on wet filter paper. Thus, CFI may facilitate a lab-based screening of lettuce genotypes for their reaction to B. lactucae inoculation (Bauriegel et al. 2014). Similar results for the lettuce-Bremia system were observed using both $\Phi_{\text {PSII }}$ and NPQ parameters (Brabandt et al. 2014). In crop species, $F_{v} / F_{m}$ parameter allowed presymptomatic detection of the leaf area infected by Xanthomonas fuscans subsp. fuscans, the causal agent of common bacterial blight of bean (Phaseolus vulgaris L.) (Rousseau et al. 2013). Infection of wheat (Triticum aestivum L.) leaves with leaf rust (Puccinia recondita) and powdery mildew (Blumeria graminis $\mathrm{f}$. sp. tritici) was detected 2 to 3 days prior to visual appearance of symptoms (Kuckenberg et al. 2009). The initial infection by both pathogens was initially accompanied by an increase in $F_{O}$ and decrease in photochemical efficiency (lower $F_{v} / F_{m}$ and $F_{v} / F_{O}$ ratios). Subsequent reduction of fluorescence absorption (smaller values of $F_{O}$ and $F_{m}$ values) was caused by the shielding effect of the mycelium and to the lesser extent by chlorophyll breakdown in affected tissue (Kuckenberg et al. 2009). There was an apparent difference between two fungal pathogens when chlorophyll fluorescence was measured in the vicinity of infections. Powdery mildew did not decrease fluorescence in the area around mycelium, while rust-infected plants showed reduced $F_{v} / F_{m}$ and $F_{v} / F_{O}$ ratios in chlorotic tissue around pustules (Kuckenberg et al. 2009).

CFI revealed presymptomatic increase in fluorescence in susceptible sugar beet (Beta vulgaris L.) leaves infected by Cercospora beticola Sacc. (Chaerle et al. 2007a; Chaerle et al. 2004), but also during first symptoms of HR observed between resistant tobacco (Nicotiana tabacum L.) and Tobacco mosaic virus (TMV) (Chaerle et al. 2004). The increased fluorescence in early stages of infection is caused by changes in the photosynthetic electron transport or the downstream metabolic reaction (Chaerle et al. 2007b). Thus, the areas of higher chlorophyll fluorescence intensity co-locate with the thermal symptoms and eventual areas of visual damage. A combined analysis of chlorophyll fluorescence and thermal imaging was used to determine photosystem operating efficiency and production of reactive oxygen species after simultaneously exposing soybean (Glycine max L. Merr.) leaves to Soybean mosaic virus (Aldea et al. 2006) and atmospheric $\mathrm{O}_{3}$.
CFI, applied to identify the interaction between spring barley (Hordeum vulgare L.) and pathogens that cause powdery mildew (B. graminis) and leaf rust (Puccinia hordei), detected genotypespecific responses to pathogen infection 3 days after inoculation. Differences in fluorescence between inoculated and control plants became more evident following pathogen development (Leufen et al. 2014). Esca disease of grapevine (Vitis vinifera L.) is caused by xylem inhabiting pathogens Phaeomoniella chlamydospora, Phaeoacremonium aleophilum, and Fomitiporia mediterranea (Christen et al. 2007). The disease impedes the water transport by clogging the xylem vessels of infected plants. CFI identified alterations in photosynthetic apparatus related to the disease 2 months before the foliar appearance of symptoms (Christen et al. 2007). CFI also detected unique changes in fluorescence of A. thaliana leaves inoculated with Pseudomonas syringae (Fig. 3) (Berger et al. 2007). A decrease in photosynthesis was detected $6 \mathrm{~h}$ after inoculation, at least $18 \mathrm{~h}$ before faint symptoms were visually observed. The changes in chlorophyll fluorescence were limited to the infected site and did not spread to other areas of the leaf (Bonfig et al. 2006). Laser-induced fluorescence transient (LIFT) (Raesch et al. 2014) was tested for presymptomatic detection of powdery mildew (caused by $B$. graminis $\mathrm{f}$. sp. tritici) on winter wheat (Bürling et al. 2012). The method was able to distinguish between resistant and susceptible genotypes already 1 day after inoculation. LIFT system can also be used outdoors to the distance of up to $50 \mathrm{~m}$.

In contrast to digital imaging, modulated CFI is not sensitive to environmental light variation that may alter the contrast of RGB images and interfere with thresholding methods (Rousseau et al. 2013). Single-channel images of chlorophyll fluorescence then can be easily segmented by automated thresholding procedures and used for the quantification of wilted, chlorotic, and necrotic areas of the leaf (Rousseau et al. 2013) (assuming homogeneous background as all chlorophyll tissue do fluoresce). Web-based resources are available for automated screening of CFI and for identifying fluorescence parameters that discriminate between plants with different reactions to pathogens (Rousseau et al. 2015).

Typically, CFI shows a finer spatial resolution than thermal imaging or digital imaging when quantifying and identifying diseaseinduced symptoms or lesions under laboratory conditions (Chaerle et al. 2007b). However, many of the chlorophyll fluorescence parameters are measured in the dark-adapted state (Maxwell and Johnson 2000). When dark adaptation of plants is needed for the accurate detection of infection (Kuckenberg et al. 2009), but is not possible or feasible to perform from a practical point of view, e.g., in the field at farm scale, the appeal of using the technique for screening decreases. Measurements of chlorophyll fluorescence kinetics obtained without predarkening can be used instead, but lightadapted signals are lower than dark-adapted signals, making them less sensitive to changes in photosynthetic response (Bauriegel and Herppich 2014).

Recent results in extracting sun-induced chlorophyll fluorescence (SIF) parameters in field conditions with portable spectroradiometers show that spectral resolution of less than $1 \mathrm{~nm}$ is needed for an accurate estimate of far-red SIF while red SIF requires spectral resolution of less than $0.5 \mathrm{~nm}$ (Julitta et al. 2016). The reliability of SIF estimates can be improved by using longer integrations times and more repeated scans. Though these results illustrate a possibility of practical application of SIF for remote sensing under field conditions, additional analyses are needed to identify limits in capturing SIF (Julitta et al. 2016).

\section{MULTI- AND HYPERSPECTRAL IMAGING}

Spectral imaging sensors detect electromagnetic waves including those not visible by the human eye such as ultraviolet (UV) radiation and infrared (IR) radiation (Fig. 1). Spectral imaging devices collect data for each pixel of the image (Fig. 4). These data can be combined to identify specific characteristics that may not be evident in the 
visible spectrum (Fig. 5). Because hyperspectral imaging sensors collect data from a larger number of narrower bands than multispectral imaging sensors, hyperspectral devices provide a higher level of spectral detail than multispectral devices. However, they also require a substantially larger capacity for storage and analysis of data and their cost is much higher particularly for systems going above $1,300 \mathrm{~nm}$.

Light landing on a leaf surface is differentially absorbed, transmitted, or reflected by the leaf depending on the leaf internal structure, chemical composition or physiological status. Measuring spectral reflectance by hyperspectral cameras can thus be used to inform on the health status of the whole plant or to quantify diseaseinfected areas of plants. Laboratory-based hyperspectral imaging system (detecting electromagnetic radiation from 400 to $1,000 \mathrm{~nm}$ ) reliably identified symptoms of head blight disease and the positions of infected kernels on ears of winter wheat that were inoculated with F. culmorum (Bauriegel and Herppich 2014; Bauriegel et al. 2011a). However, hyperspectral imaging was not able to distinguish be- tween healthy and infected kernels in the fully ripe stage (Bauriegel et al. 2011b). Because the use and the analysis of the $400 \mathrm{~nm}$ to $1,000 \mathrm{~nm}$ spectral range is time-consuming, using only spectral subranges ( 665 to $675 \mathrm{~nm}$ and 550 to $560 \mathrm{~nm}$ ) was recommended for the practical outdoor classification of kernels' health (Bauriegel et al. 2011b). Under laboratory conditions, disease symptoms caused by $C$. beticola on leaves of sugar beet were successfully identified using hyperspectral imaging (Bergsträsser et al. 2015). While photosynthesis in leaves of field bean (Vicia faba L.) was significantly reduced after their infection with Botrytis fabae, a fungus that causes chocolate spot disease, changes in spectral reflectance were only observed after visual symptoms of disease appeared on inoculated leaves. These changes were attributed to collapse of leaf cell structure as the fungus spread (Malthus and Madeira 1993). Hyperspectral analysis of Stagonospora nodorum blotch disease (caused by Parastagonospora nodorum (Berk.)) in durum wheat (Triticum turgidum L.) allowed differentiation between healthy and diseased tissue already $48 \mathrm{~h}$ after inoculation
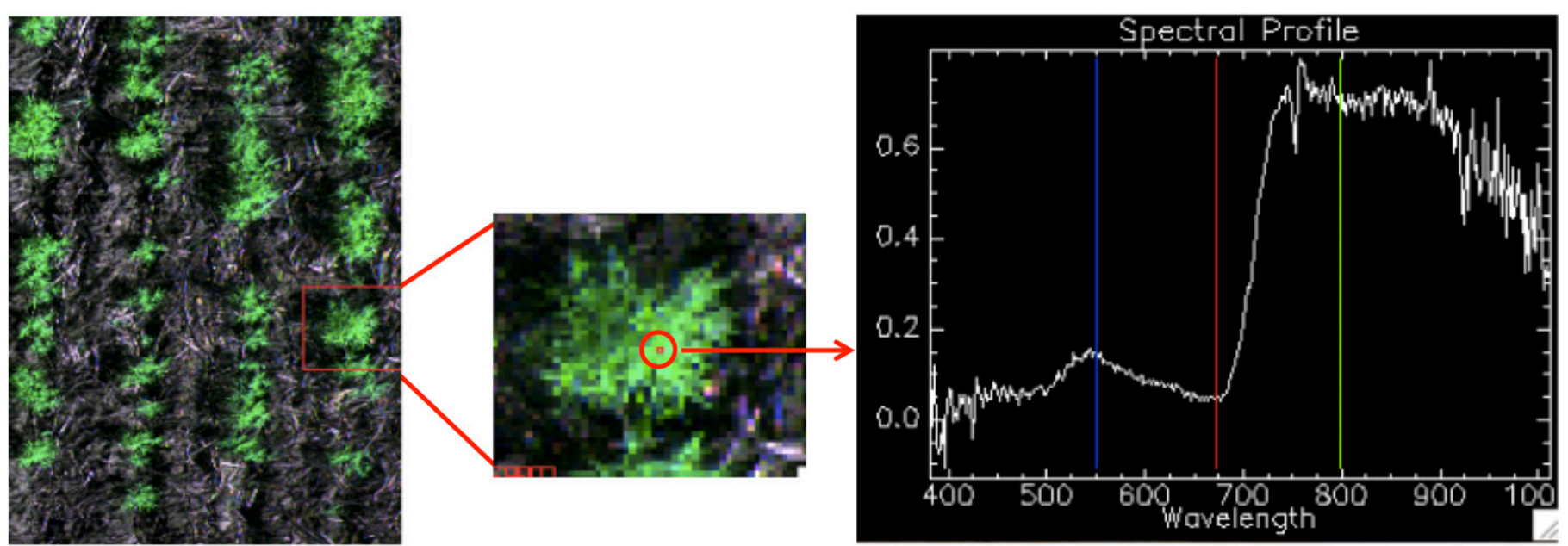

\section{FIGURE 4}

Hyperspectral image captured with the Phenomobile ground platform (Deery et al. 2014) using a hyperspectral line scanner (Micro-VNIR, Headwall Photonics, MA) over white lupine (Lupinus albus L.) (left) presented as a false color composition. The close-up image (middle) shows a single plant and a pixel that is highlighted (in red circle). Each pixel in the image consists of 340 bands (right) from 400 to 1,000 nm. The red, green, and blue lines represent the band selection used in the false color composition: red, $670 \mathrm{~nm}$; green, $800 \mathrm{~nm}$; and blue, $550 \mathrm{~nm}$. Hyperspectral data can be combined to detect, identify, and/or quantify diseases.

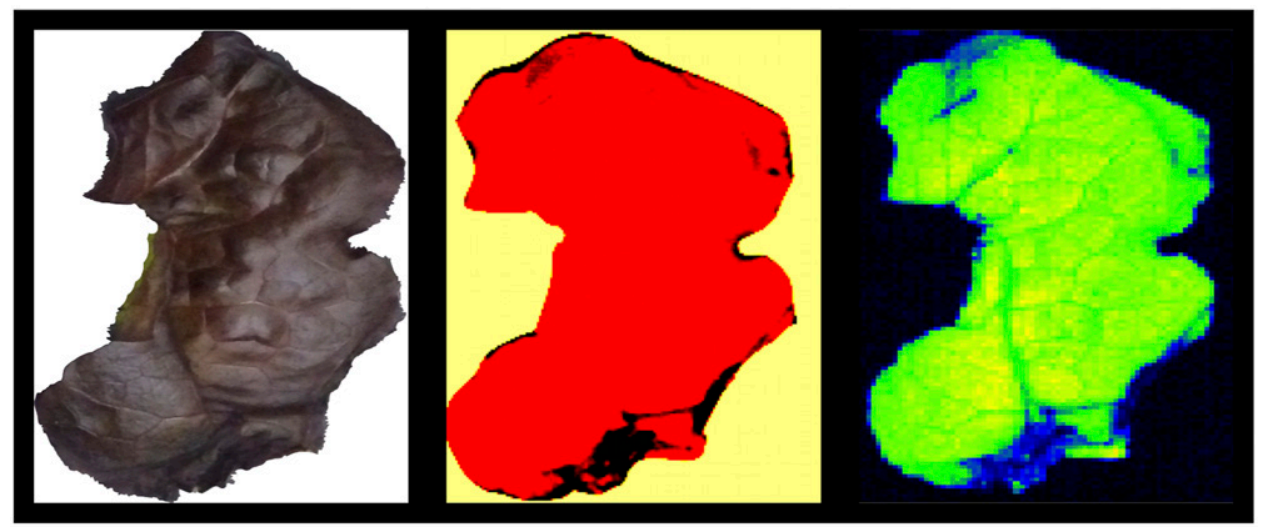

\section{FIGURE 5}

Damage on red-leaf lettuce caused by Pseudomonas sp. as detected by digital imaging (RGB, left), hyperspectral imaging (HSI, middle), and chlorophyll fluorescence imaging (CFI, right). Note that the damage is difficult to see via RGB imaging on red-colored leaves, while pseudo-color images of $\mathrm{HSI}$ and CFI clearly show the affected areas as black or dark blue regions. HSI was obtained by combining wavelengths at 677,732 , and $952 \mathrm{~nm}$, while $\mathrm{CFI}$ shows the $F_{v} / F_{m}$ parameter. CFI was performed $24 \mathrm{~h}$ later than $\mathrm{HSI}$; therefore $\mathrm{CFI}$ detected somewhat larger areas of damage. Images have slight distortions caused by analytical tools (I. Simko, unpublished data). 
(Iori et al. 2015). A hyperspectral microscopic approach was developed to investigate reaction of barley leaves to inoculation with spores of $B$. graminis $\mathrm{f}$. sp. hordei that causes powdery mildew (Kuska et al. 2015). Spectral differences between healthy and diseases genotypes were observed, indicating that this approach may be used to study early processes of pathogenesis.

Multispectral imaging (a more affordable technology) was applied for remote sensing of the health status of field-grown wheat cultivated in the presence of powdery mildew (B. graminis) and leaf rust ( $P$. recondita) pathogens (Franke and Menz 2007). Normalized difference vegetation index (NDVI) classified the data into areas showing different levels of disease severity. The accuracy of classification ranged from 56.8 to $88.6 \%$ when compared with the ground truth data (Franke and Menz 2007). Hyperspectral reflectance measured with nonimaging spectroradiometer could differentiate with up to $97 \%$ accuracy healthy leaves of sugar beet from those inoculated by C. beticola, Uromyces betae, or Erysiphe betae causing Cercospora leaf spot, sugar beet rust, and powdery mildew (Rumpf et al. 2010). Presymptomatic detection of the plant diseases showed the classification accuracy between 65 and 90\% (Rumpf et al. 2010). When analyses of the same plant-pathogen systems were performed with hyperspectral imaging, classification accuracy for the three pathogens during disease progress on leaves was lowest for sugar beet rust $(61.7 \%)$, but substantially higher for powdery mildew (90.2 to $97.2 \%$ ) and Cercospora leaf spot (89.0 to 98.9\%) (Mahlein et al. $2012 \mathrm{~b}$ ). Spectral reflectance in the visible and near-infrared range allowed differentiation between the three diseases (Mahlein et al. 2012b). Multispectral imaging sensors were used to analyze orange trees (Citrus $\times$ sinensis L.) infected by Huanglongbing disease that is caused by species of bacteria from the genus Liberibacter (GarciaRuiz et al. 2013; Sankaran et al. 2013). The reflectance at $710 \mathrm{~nm}$ (farred light) provided the maximum separation of healthy trees from infected. This wavelength allowed good classification at different spatial resolutions when sensors were mounted on a land-based vehicle (Sankaran et al. 2013), an unmanned aerial vehicle, or an aircraft (Garcia-Ruiz et al. 2013).

Similarly the occurrence of wheat streak mosaic disease (caused by Wheat streak mosaic virus) in fields assessed with satellite images (Mirik et al. 2013) allowed the classification of areas of fields into healthy or diseased with an accuracy ranging from 89.5 to $99.1 \%$ when compared with the ground truth based on laboratory analyses of wheat samples collected in fields (Mirik et al. 2011).

Aerial multispectral and hyperspectral imagery were compared for their abilities to identify areas of cotton (Gossypium hirsutum L.) fields that were infected with cotton root rot caused by the soilborne fungus Phymatotrichum omnivorum. Results obtained with 3-band multispectral imagery and 128-band hyperspectral imagery were the same; with $95 \%$ accuracy of correctly identifying root rot areas and $96.7 \%$ accuracy of identifying noninfected areas (Yang et al. 2010). Because a 3-band multispectral imagery instruments are cheaper and more widely available, using this method was recommended for practical detection of cotton root rot. However, it was noted that hyperspectral imagery has the potential advantage in early detection of the disease and in distinguishing cotton root rot from other co-occurring stresses (Yang et al. 2010).

Hyperspectral analyses were also applied to investigate relationships between spectral indices and infestation of plants by pests. A strong positive relationship was observed between NDVI and the stress in wheat $\left(R^{2}=0.969\right)$ caused by the density of the adult stage of sunn pest (Eurygaster integriceps Put) (Genc et al. 2008). A somewhat weaker relationship $\left(R^{2}=0.62\right.$ to 0.85$)$ was observed between spectral indices and greenbug (Schizaphis graminum Rondani) density in infected winter wheat (Mirik et al. 2006). When compared with undamaged wheat canopy, canopy damaged by greenbug had lower reflectance in the near infrared spectrum and higher reflectance in the visible range spectrum. The use of NDVI alone, however, is limited by the fact that the index may be cofounded with other changes happening in plants, not only those caused by diseases or pests.

More recently, high-resolution hyperspectral airborne imagery was applied for the early detection of red leaf blotch (Polystigma amygdalinum PF Cannon) in almond (Prunus dulcis (Mill.) D.A. Webb) orchards (López-López et al. 2016). Integrating vegetation indices with positive discrimination for the disease into a nonlinear support vector machine was the most effective method $(80 \%$ accuracy of the classification) for separating healthy trees and trees with incipient infection.

Though hyperspectral imaging is a valuable technology for detecting abiotic and biotic stresses of plants, acquisition and processing of such images is still nowadays substantially slower than for images obtained with other types of cameras. Beside storage capacity, analyses of hyperspectral images create statistical and computational challenges due to multidimensionality of datasets. Because highly sensitive sensors, combined with large data storage capacity and fast computers are needed, cost is the limiting factor for working with hyperspectral imaging for many laboratories. More affordable multispectral sensors, which collect data from fewer, but wider bands are therefore more frequently used at present in phytopathology. In addition, it was suggested (Mewes et al. 2011) that for detection of plant stress due to diseases it may not be necessary to use hyperspectral cameras with a broad spectrum. The authors argue that narrow spectral bands of hyperspectral images are highly correlated (auto-correlation in the signal for close enough wavelengths) and therefore possibly provide similar information.

\section{THERMAL IMAGING (INFRARED THERMOGRAPHY, IRT)}

Plant infection by pathogens may be accompanied with changes in local temperature, which can be measured by infrared thermography (Fig. 6). Cameras used for far-infrared imaging (thermal imaging) usually detect electromagnetic radiation with the wavelength from about 9 to $14 \mu \mathrm{m}$ (Fig. 1). High temperature shows areas with closed stomata and limited evaporation rate, while
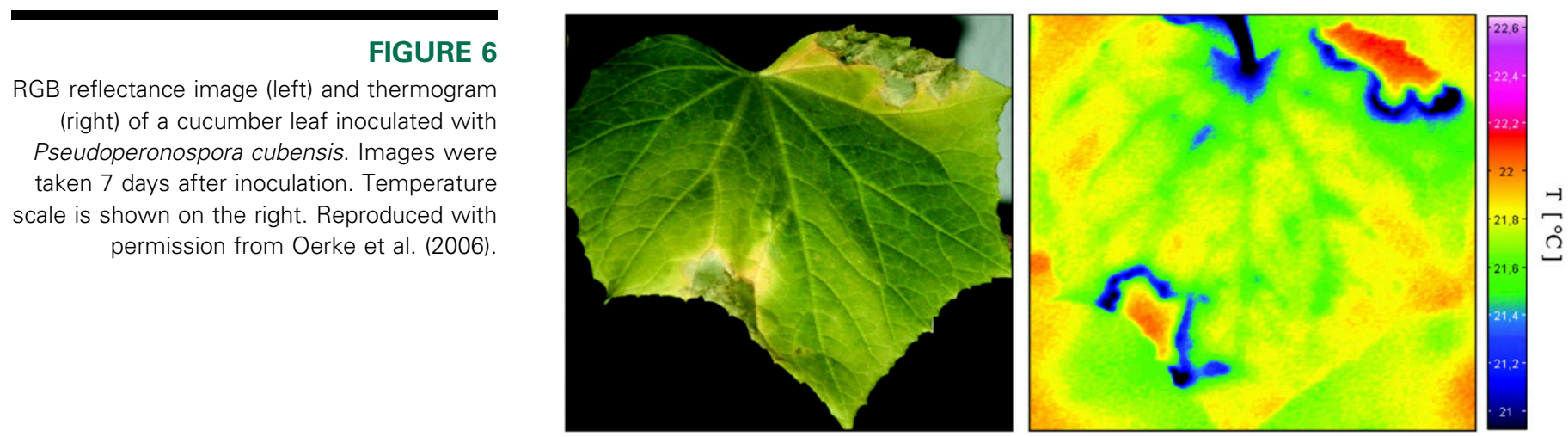
low temperature indicates areas with open stomata or damaged tissue (Chaerle et al. 2007b). Pathogens can influence stomatal behavior either directly through specific compounds or indirectly by interfering with water transport (Chaerle et al. 2004, 2007b). While early stages of HR are accompanied by increase in temperature (Chaerle et al. 1999, 2004), susceptible interaction between plant and pathogen usually leads to early decrease in temperature, followed by a gradual increase (Chaerle et al. 2004; Lindenthal et al. 2005).

For example, HR of tobacco leaves to TMV can be detected by IRT $8 \mathrm{~h}$ before cell death can visually be observed. This presymptomatic increase in temperature (Chaerle et al. 2004) remained detectable as a halo around ongoing necrosis, gradually losing intensity until necrosis was complete (Chaerle et al. 1999). The increase in leaf temperature was shown to be related to stomatal closure (Chaerle et al. 2001). Stomatal closure in pathogen-infected plants could also be caused either by compounds produced by pathogens (Di Giorgio et al. 1996) or by those produced by plants, e.g., compounds in a resistance-signaling pathway such as salicylic acid (Chaerle et al. 1999, 2001). When results of thermal imaging at early stages of plant-pathogen interaction were compared with the HR-related necrosis visually observed later on, the coincidence between estimates of the final size and the location of HR-related necrosis was high, indicating that changes in leaf temperature provide an approximate 'preview' of the final HR extension (Chaerle and Van Der Straeten 2000).

Interaction between the obligate biotrophic pathogen (Pseudoperonospora cubensis) that causes downy mildew and cucumber (Cucumis sativus L.) was visualized using digital infrared thermography (Lindenthal et al. 2005). Presymptomatic decrease in temperature was observed on leaf areas colonized by the pathogen due to abnormal stomatal opening. A negative linear relationship $\left(R^{2}=0.58\right)$ was determined between leaf temperature and transpiration. As disease progressed, an increase in leaf temperature was noted due to the lack of natural cooling in necrotic tissue. Because different stages of plant-pathogen interaction affect leaf temperature dissimilarly, a high heterogeneity in temperature distribution was observed within the infected leaves. Nevertheless, the maximum temperature difference (MTD) within a thermogram of cucumber leaves allowed for the presymptomatic discrimination between healthy and infected leaves (Lindenthal et al. 2005). Conditions increasing the transpiration rate led to detection of disease at early stages. MTD was also strongly associated with scab (Venturia inaequalis) development on apple (Malus domestica Borkh.) leaves (Oerke et al. 2011). High coefficients of determination were observed between both MTD and the size of infection $\left(R^{2}=0.85\right)$ and the overall disease severity $\left(R^{2}=0.71\right)$. Similar results were observed for the sugar beet-C. beticola system, with lower temperatures detected in presymptomatic spots of susceptible plants (Chaerle et al. 2004).

Contrasting results were obtained for spring barley-powdery mildew (B. graminis) system, where increase of leaf temperature was observed 3 days after infection, more than 3 days before the appearance of visual symptoms (Klém et al. 2015). Reaction of Nicotiana benthamiana L. to inoculation with two strains of Pepper mild mottle virus with different levels of virulence indicates that the earliest temperature increase may be caused by a systemic plant response to the virus infection. This reaction involves the control of water loss as the temperature increase was correlated with a decrease in stomatal opening (Chaerle et al. 2006).

Substantial differences were observed in reactions of plants to pathogens even under controlled environmental conditions; thus, it is not possible to draw a simple conclusion how temperature of leaves (or other plant organs) changes during plant-pathogen interaction. Factors such as a pathogen effect on a plant, a plant resistance response, and a stage of their interaction play critical (but sometime opposing) roles in changes of temperature. Therefore, for a practical application in phytopathology, IRT needs to be tailored for the particular plant-pathogen system.
Use of thermal imaging for the detection of plant diseases in the field conditions has been limited so far. The main reason is probably a high sensitivity of IRT to environmental factors such as ambient temperature, sunlight, precipitation, wind, and background thermal radiation. It was suggested that IRT alone may not be suitable for detection of diseases in the field. Quantification of disease, however, has been improved by combining IRT sensors with other remote sensing methods that identify changes in plants (Oerke et al. 2006). Thermal infrared region $(8,000$ to $15,000 \mathrm{~nm})$ was suitable for detecting olive (Olea europea L.) trees infected with soilborne fungus Verticillium dahliae Kleb. because decrease in transpiration caused by the pathogen infection induced stomatal closure, thus reducing evaporative cooling and increasing canopy temperature (Calderón et al. 2015). Early stages of disease development could be detected using crop water stress index calculated by combining data from the thermal imagery, spectral imagery, and chlorophyll fluorescence (Calderón et al. 2013).

\section{MAGNETIC RESONANCE IMAGING (MRI)}

MRI uses strong magnetic fields and radio waves to form threedimensional (3D) images of the objects. MRI can be used to evaluate internal tissue structure and water distribution in plants (Chaerle and Van Der Straeten 2001). Rhizoctonia crown and root rot (RCRR) is a sugar beet disease caused by the soilborne basidiomycete Rhizoctonia solani. Below ground symptoms can traditionally be detected only by destructively removing the entire root system from the soil. Nuclear MRI was successfully applied to nondestructively identify symptoms caused by both RCRR (Fig. 7) and the beet cyst nematode Heterodera schachtii without removing plants from the growth media (Hillnhütter et al. 2012). Similarly, the effect of the Cercospora leaf spot disease on sugar beet taproot development was detected with MRI 14 days postinoculation, though differences in leaf size between plants with different levels of resistance were still small (Schmittgen et al. 2015). Evaluations with MRI are, however, relatively uncommon in plant pathology due to high-complexity and nonportability of instruments. If root systems are analyzed, the plants need to be cultivated in a substrate devoid of ferrous particles and in containers that fit into an MRI instrument. Because this method can to date only be used for evaluation of plants grown in pots, its use is limited to development of mechanistic models of plant-disease interaction.

\section{X-RAY IMAGING}

Electromagnetic radiation with wavelength from about 10 to 100 pm is called hard X-ray, while the radiation with wavelength between $100 \mathrm{pm}$ to $10 \mathrm{~nm}$ is called soft X-ray (Fig. 1). Imaging system based on soft X-ray has been tested for detection of fungal infection with Aspergillus niger, A. glaucus group, and Penicillium spp. in harvested wheat kernels. Grains infected with fungus showed changes in density that were detected on the X-ray images. The method provided 92.2 to $98.9 \%$ accuracy in classifying fungal-infected kernels and more than $82 \%$ classification accuracy in identifying healthy kernels (Narvankar et al. 2009). An apparatus based on soft $\mathrm{X}$-rays has been developed for nondestructive analysis of a plant root system (McDonald and Michaels 2007). In this approach, X-ray radiation passes through roots thus generating an image that can be captured. The apparatus could detect changes in a root system related to an infection by a pest or a pathogen. Analyzed plants, however, have to be grown in a special, low density substrate, that enhances the visibility of the root system in the image (McDonald and Michaels 2007). A progress in the development of contrast-enhancing techniques facilitated improvements in nanoscale X-ray imaging systems with high spatial resolution that can be used for studying plant-pathogen at subcellular level in 3D (Sakdinawat and Attwood 2010). Despite progress in the use of X-ray imaging in biological 
sciences, this technique is not commonly applied in plant pathology, possibly due to its high cost, use of X-ray radiation, relatively low resolution, and limited portability of instruments.

\section{ULTRASOUND}

Sound waves with frequencies above the limit of human hearing can be used for nondestructive testing. The transmittance, absorption, or reflection of sound waves allows detecting structure of material and its changes. For example, the ultrasound analyzer system that detects an acoustic pulse after it has passed through the seed was successfully used to identify soybean (Glycine max L. Merr.) seeds with asymptomatic infections of seedborne fungi (Aspergillus spp. and Penicillium spp.), or Phomopsis seed decay (PSD) (Phomopsis longicolla, Diaporthe phaseolorum var. sojae, and D. phaseolorum var. caulivora) (Walcott et al. 1998). The peak value of the ultrasound signal parameter that indicates seed weight decreased linearly as the incidence of infection by storage fungi or PSD increased $\left(R^{2}=0.85\right.$ and 0.82 , respectively). This relationship suggests decreased seed weight in infected, but still asymptomatic seeds. The ultrasound signal parameters that indicate softer seeds also increased with increasing rate of seed infection, though coefficients of determination were lower $\left(R^{2}=0.42\right.$ to 0.59 ) than those for the parameter related to seed weight (Walcott et al. 1998). The authors noted that this technology may be able to detect only particular pathogens in seeds and that the practical adaptation of the technology will require considerable developmental effort.

\section{DETECTION OF VOLATILE COMPOUNDS}

The volatile compounds released by infected plants are different from those released by healthy plants due to changes in plant physiology. Technology based on detection of these compounds could facilitate the real-time analysis of plant health. The techniques used for detection of volatile compounds are frequently based on gas chromatography (GC).

A conducting polymer gas sensor array (electronic nose, e-nose) was evaluated for its ability to detect three postharvest diseases (gray mold caused by Botrytis cinerea, anthracnose caused by Colletotrichum gloeosporioides, and Alternaria rot caused by Alternaria sp.) on blueberry (Vaccinium virgatum Aiton) fruits 6 to 10 days after inoculation (Li et al. 2010). The system showed 100\% accuracy in classifying healthy or diseased fruits into two respective categories. Some misclassification, however, was observed among the three groups of diseases thus decreasing the overall correct classification to approximately $90 \%$. Six volatile compounds were identified as contributing the most to observed differences ( $\mathrm{Li}$ et al. 2010). An e-nose was used to distinguish among volatile compounds emitted by leaves of three plant species (cucumber, Cucumis sativus L.; pepper, Capsicum annum L.; and tomato, Solanum lycopersicum L.) subjected to three types of damages caused by mechanical injury, pest, or disease. The e-nose could differentiate between damaged and healthy plants, and also among those damaged by the three different means (Laothawornkitkul et al. 2008). Changes in sesquiterpenes were detected after infection of maize ears with Fusarium species (Becker et al. 2014). These volatile markers could be used for early, nondestructive detection of fungal infection in the field or during postharvest processes using ion mobility spectrometers (Becker et al. 2013).

The detection of volatile compounds shows a promising potential for phenotyping of plant diseases. The biggest challenge is, however, high temporal and spatial variability of emissions due to environmental factors such as temperature, light intensity, water, availability of nutrients (Niederbacher et al. 2015), and wind. In addition, volatile compounds released by different organs (e.g., flowers, fruits, leaves, and stems) may differ. This needs to be considered in experimental set-ups when testing plants with dissimilar proportions of these organs. To improve reliability of results, it was suggested to combine phenotyping of plant volatile compounds with other noninvasive sensing techniques (Niederbacher et al. 2015), e.g., spectral, thermal, and chlorophyll fluorescence imaging.

\section{CHALLENGES AND FUTURE DEVELOPMENT}

Despite progress in development of sensor-based methods for detection of plant-pathogen interaction, certain problems are still encountered in a large part due to variability in plants (e.g., position and angle of leaves), pathogens (e.g., different symptoms), and environment (particularly under field conditions). In addition, the accuracy and precision of phenotyping could be affected by a combination of two or more pathogens causing similar plant response (e.g., necrotic lesions) or if the plant reaction is similar to those caused by abiotic factors or natural changes occurring during growth and development (e.g., plant senescence). It is important to understand that remote sensing provides additional tools and approaches for diagnosis of plant diseases, but there is not a single
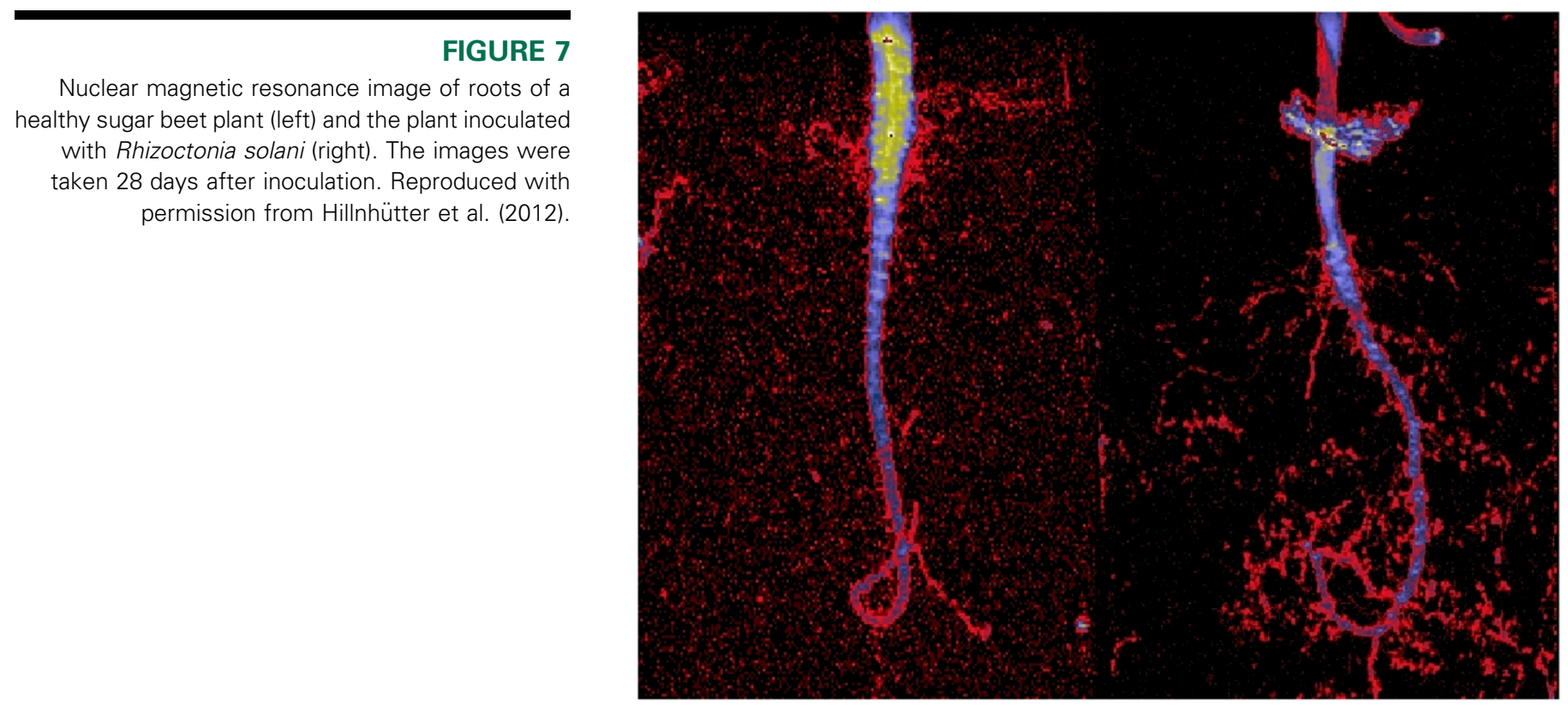

Vol. 107, No. 1, 2017 
method that is perfect for the identification of every disease. Phenotyping is usually more exact in closed systems where conditions are controlled and only a single pathogen is interacting with a plant. Under field conditions, where the abiotic stress can cause similar effects to the disease or with the possibility of pathogenesis of various pathogens having similar physiological manifestation, it is necessary to use all the available tools and information in order to provide the right assessment. For example, changes in chlorophyll fluorescence could be caused by a decline in the photosynthetic capacity driven by a pathogen or by nutrient deficiencies, water stress or simply because of the phenology of the crop (i.e., canopy senescence). Combining CFI with other techniques such as hyperspectral imaging for determining the nutrition status of the crop, thermal imaging for the water status and prior knowledge of the actual crop management provides enough information to detect anomalies from the expected signal behavior that can indicate that these are caused by a particular pathogen.
Recently, several sensor-based, automated or semi-automated platforms were developed for nondestructive phenotyping that can also be used for the detection of plant-pathogen interaction. These platforms normally integrate one or more of the above-described imaging systems and perform high-throughput phenotyping under field or controlled environment conditions. Some platforms are commercial (e.g., PlantScreen from Photon Systems Instruments, Brno, Czech Republic or Scananalyser ${ }^{3 \mathrm{D}}$ from LemnaTec $\mathrm{GmbH}$, Aachen, Germany) while others are developed directly by phenotyping laboratories (e.g., PlantScan and Phenomobile developed by the High Resolution Plant Phenomics Centre, Canberra, Australia). The high resolution scans obtained by platforms such as PlantScan (Sirault et al. 2013) allow the recreation of 3D models of single plants (Fig. 8) where some of the multiple imaging modalities discussed above can be overlaid on single leaves and organs. At the field level, Phenomobile (Fig. 9) integrates sensors such as hyperspectral imaging, LiDAR for 3D plant reconstruction and thermal imaging (Deery

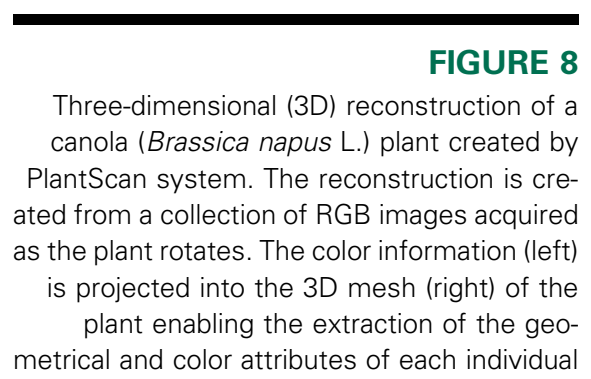

leaf or the entire plant.
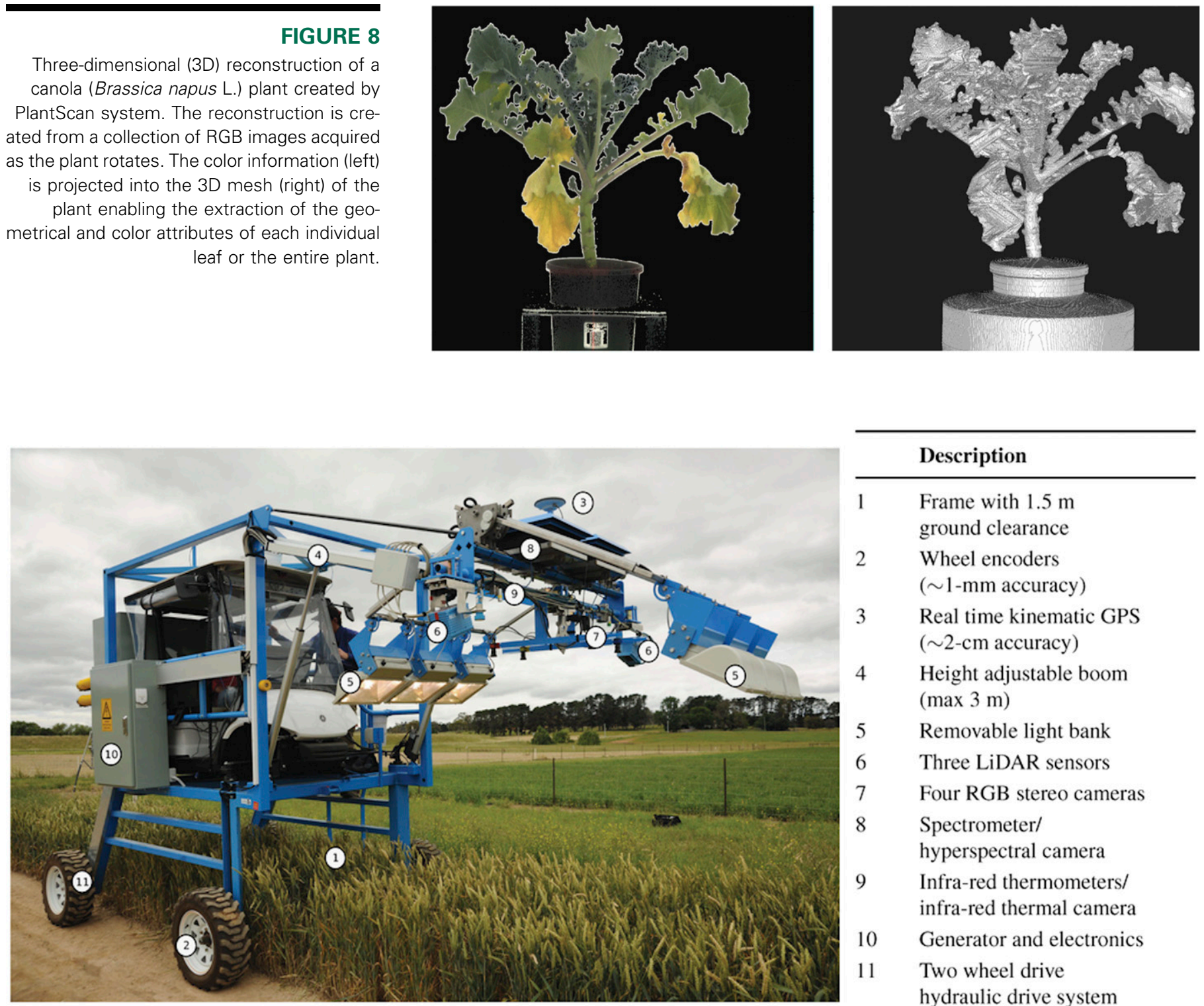

\begin{tabular}{|c|c|}
\hline & Description \\
\hline 1 & $\begin{array}{l}\text { Frame with } 1.5 \mathrm{~m} \\
\text { ground clearance }\end{array}$ \\
\hline 2 & $\begin{array}{l}\text { Wheel encoders } \\
(\sim 1 \text {-mm accuracy })\end{array}$ \\
\hline 3 & $\begin{array}{l}\text { Real time kinematic GPS } \\
(\sim 2-\mathrm{cm} \text { accuracy })\end{array}$ \\
\hline 4 & $\begin{array}{l}\text { Height adjustable boom } \\
(\max 3 \mathrm{~m})\end{array}$ \\
\hline 5 & Removable light bank \\
\hline 6 & Three LiDAR sensors \\
\hline 7 & Four RGB stereo cameras \\
\hline 8 & $\begin{array}{l}\text { Spectrometer/ } \\
\text { hyperspectral camera }\end{array}$ \\
\hline 9 & $\begin{array}{l}\text { Infra-red thermometers/ } \\
\text { infra-red thermal camera }\end{array}$ \\
\hline 10 & Generator and electronics \\
\hline 11 & $\begin{array}{l}\text { Two wheel drive } \\
\text { hydraulic drive system }\end{array}$ \\
\hline
\end{tabular}

\section{FIGURE 9}

Phenomobile is a field phenotyping platform that integrates 3D imaging and LiDAR, hyperspectral and thermal imaging cameras on a buggy designed to scan typical plots in breeding trials. The information collected is geo-referenced using high accuracy global positioning. Integrated data from multiple sensors collected with phenotyping platforms can be used for detection of plant diseases. Reproduced with permission from Deery et al. (2014). 
et al. 2014). These platforms also permit multitemporal resolution for keeping track of changes in architecture and physiology that could allow for the better definition of the pathology of different genotypes. Because high-resolution, high-throughput phenotyping platforms collect terabytes of data, they need to be coupled with computers, software, and statistical approaches that are able to handle very large volumes of data quickly. Beside managing data streams, other important factors need to be considered when developing integrated, high-throughput, field-based phenotyping platforms. These factors include standardized protocols for testing and calibration of promising instruments, overcoming barriers when integrating instruments with different, often proprietary formats, and maintaining balance among numerous lines of research (White et al. 2012).

\section{USING PHENOMICS TO LINK EPIDEMIOLOGICAL MODELS TO CROP YIELD}

Advances in automation allow for the integration of complementary sensing technologies, thus leading to a development of complex image-analysis workflows. New phenomics technologies are permitting direct and continuous measurements of functional and morphological crop attributes in the field rapidly, cheaply and easily; including those related to disease development that are measured at multiple temporal and spatial scales (Deery et al. 2014). The major challenge is to use this multidimensional information to predict crop performance but also to help in deciphering confounding effects between abiotic and biotic stresses, e.g., reduced transpiration due to soil moisture from reduced transpiration due to disease. The intricacy of the feedback loops between plant and pathogen and the variable environment render our understanding of the dynamics of epidemics difficult without the use of modeling approaches. Up to now, phenotyping techniques and approaches have been considered individually and independently, without focusing on combining these heterogeneous datasets to provide a more comprehensive picture of the plant pathogen interaction.

We argue that epidemiological modeling should be considered as natural complements to phenomics tools, allowing one to investigate complex processes more readily. As such, any modeling framework used for assimilating phenotyping data should be regarded as a natural extension of the technologies described in this review. Only modeling can help sieve through the complexity of the collected data, in part due to its ability to simultaneously handle large number of hosts, pathogens, and environmental variables but most importantly because of its ability to handle multiple, simultaneous interactions.

From a modeling point of view, a pathosystem can be described by three main entities (Garin et al. 2013): a functional-structural crop, a pathogen population, and a physical environment-each entity with its own model and operating at different temporal and spatial scales. The environment, in particular the microenvironment around organs within a canopy or phylloclimate (Chelle 2005), needs to be measured precisely as it is key in determining the dynamic of host-pathogen interaction at the leaf level. In fact, disease progression is largely mediated by the canopy architecture or the spatial density of plant organs as it influences the dispersal of pathogens and/or infection of new host tissue. For example, it was observed that plant height was negatively correlated with Septoria epidemics (Eyal 1971), thus indicating that the introduction of high yielding, short straw cultivars in the 1970s had led to more favorable conditions for these foliar wheat diseases. It has also been suggested that the vertical progress of Septoria was favored by reduced distance between leaves because it exposes emerging leaves to more splashed pycnidiospores (Bahat et al. 1980; Pielaat et al. 2002). The interaction of the 3D canopy with the external environment can also be more or less conducive to the production of secondary inoculum during successive infection cycles. The disease epidemic itself can change the density and architecture of canopies thus affecting a microclimate within the canopy and influencing further progression of the epidemic (Carretero et al. 2010). To date, little of this dynamic information is used in crop breeding programs to account for resistance or resilience of particular genotypes to specific pathogens.

Assimilating successive measurements of canopy architecture and sensing of physiological functions into realistic models provides an opportunity to augment traditional crop improvement methods by enabling inferences about pathosystems. By integrating these measurements with a priori knowledge of crop phenology and epidemiology of the pathogen, models provide a framework for interpretation of real observations. For example, simulation of disease progress can be augmented by field examinations to correct estimates of disease severity. If the modification of parameters determining predicted severity cannot fall within predetermined limits, it could be an indication of additional nonbiotic constraints with the crop, such as drought stress. However, this requires sufficient epidemiological realism to be integrated into the underlying mathematical models. A number of models have aimed at calculating the duration and the extent of the diseaseinduced loss of green area, a main determinant of yield loss caused by many foliar diseases (Paveley 1999; Waggoner and Berger 1987); these models were successfully validated on winter wheat infected by Septoria tritici (leaf blotch), Puccinia striiformis (yellow rust), B. graminis (powdery mildew), and Puccinia triticina (brown rust) (Audsley et al. 2005). It is thus natural to consider augmenting these models with observations collected using advanced sensing instruments mounted on phenotyping platforms to compare the measured to the expected level of disease and help scientists and/or farmers with decisions on the most efficient cause of green leaf area loss.

\section{CONCLUSIONS}

Use of sensing technologies for detecting specific phenotypic reactions occurring during plant-pathogen interaction become more frequent in recent years. Application of sensor-based phenomics tools for accurate detection of plant disease, however, will make an effect not only on fields of plant pathology and genetics, it will also have a clear impact on postharvest quality (Simko et al. 2015), agronomy, and applications such as precision agriculture. Remote sensing techniques in a combination with weather monitoring systems, diagnostic assays, and appropriate epidemiological models will provide tools for early detection of diseases in crops thus allowing for timely treatments and/or localized treatments of plants, hence reducing the use of agrochemicals. Access to real data on plant assimilation, development, and health status will positively affect farm management, development of more sustainable farming practices, and forecasting of cash flow.

\section{LITERATURE CITED}

Aldea, M., Frank, T. D., and DeLucia, E. H. 2006. A method for quantitative analysis of spatially variable physiological processes across leaf surfaces. Photosynth. Res. 90:161-172.

Anderson, A. J., Stack, W. R., Liu, S., Waldron, L. B., Fjeld, D. A., Coyne, C., Moreno-Sevilla, B., Fetch, M. J., Song, J. Q., Cregan, B. P., and Frohberg, C. R. 2001. DNA markers for Fusarium head blight resistance QTLs in two wheat populations. Theor. Appl. Genet. 102:1164-1168.

Araus, J. L., and Cairns, J. E. 2014. Field high-throughput phenotyping: The new crop breeding frontier. Trends Plant Sci. 19:52-61.

Audsley, E., Milne, A., and Paveley, N. 2005. A foliar disease model for use in wheat disease management decision support systems. Ann. Appl. Biol. 147:161-172.

Bahat, A., Gelernter, I., Brown, M., and Eyal, Z. 1980. Factors affecting the vertical progression of Septoria leaf blotch in short-statured wheats. Phytopathology 70:179-184.

Bauriegel, E., Brabandt, H., Gärber, U., and Herppich, W. 2014. Chlorophyll fluorescence imaging to facilitate breeding of Bremia lactucae-resistant lettuce cultivars. Comput. Electron. Agric. 105:74-82.

Bauriegel, E., Giebel, A., Geyer, M., Schmidt, U., and Herppich, W. 2011 b. Early detection of Fusarium infection in wheat using hyper-spectral imaging. Comput. Electron. Agric. 75:304-312.

Bauriegel, E., Giebel, A., and Herppich, W. 2012. Rapid Fusarium head blight detection on winter wheat ears using chlorophyll fluorescence imaging. J. Appl. Bot. Food Qual. 83:196-203. 
Bauriegel, E., Giebel, A., and Herppich, W. B. 2011a. Hyperspectral and chlorophyll fluorescence imaging to analyze the impact of Fusarium culmorum on the photosynthetic integrity of infected wheat ears. Sensors (Basel Switzerland) 11:3765-3779.

Bauriegel, E., and Herppich, W. B. 2014. Hyperspectral and chlorophyll fluorescence imaging for early detection of plant diseases, with special reference to Fusarium spec. infections on wheat. Agriculture 4:32-57.

Becker, E.-M., Herrfurth, C., Irmisch, S., Köllner, T. G., Feussner, I., Karlovsky, P., and Splivallo, R. 2014. Infection of corn ears by Fusarium spp. induces the emission of volatile sesquiterpenes. J. Agric. Food Chem. 62:5226-5236

Becker, E.-M., Karlovsky, P., and Splivallo, R. 2013. Volatile biomarker for the detection of mycotoxin-producing fungal pathogens in maize plants (original in German; "Volatile Biomarker Für Die Detektion Von Mykotoxin Produzierenden Pilzlichen Pathogenen Bei Maispflanzen”). Patent DE102012204237 A1. The University of Göttingen, Germany.

Berger, S., Benediktyová, Z., Matouš, K., Bonfig, K., Mueller, M. J., Nedbal, L., and Roitsch, T. 2007. Visualization of dynamics of plant-pathogen interaction by novel combination of chlorophyll fluorescence imaging and statistical analysis: Differential effects of virulent and avirulent strains of P. syringae and of oxylipins on A. thaliana. J. Exp. Bot. 58:797-806.

Bergsträsser, S., Fanourakis, D., Schmittgen, S., Cendrero-Mateo, M. P., Jansen, M., Scharr, H., and Rascher, U. 2015. HyperART: Non-invasive quantification of leaf traits using hyperspectral absorption-reflectancetransmittance imaging. Plant Methods 11:1-17.

Bock, C., Poole, G., Parker, P., and Gottwald, T. 2010. Plant disease severity estimated visually, by digital photography and image analysis, and by hyperspectral imaging. Crit. Rev. Plant Sci. 29:59-107.

Bonfig, K. B., Schreiber, U., Gabler, A., Roitsch, T., and Berger, S. 2006. Infection with virulent and avirulent $P$. syringae strains differentially affects photosynthesis and sink metabolism in Arabidopsis leaves. Planta 225:1-12.

Brabandt, H., Bauriegel, E., Gaerber, U., and Herppich, W. 2014. $\Phi_{\text {PSII }}$ and NPQ to evaluate Bremia lactucae infection in susceptible and resistant lettuce cultivars. Sci. Hortic. (Amsterdam) 180:123-129.

Bürling, K., Hunsche, M., and Noga, G. 2012. Presymptomatic detection of powdery mildew infection in winter wheat cultivars by laser-induced fluorescence. Appl. Spectrosc. 66:1411-1419.

Calderón, R., Navas-Cortés, J. A., Lucena, C., and Zarco-Tejada, P. J. 2013. High-resolution airborne hyperspectral and thermal imagery for early detection of Verticillium wilt of olive using fluorescence, temperature and narrow-band spectral indices. Remote Sens. Environ. 139:231-245.

Calderón, R., Navas-Cortés, J. A., and Zarco-Tejada, P. J. 2015. Early detection and quantification of Verticillium wilt in olive using hyperspectral and thermal imagery over large areas. Remote Sens. 7:5584-5610

Carretero, R., Serrago, R. A., Bancal, M. O., Perelló, A. E., and Miralles, D. J. 2010. Absorbed radiation and radiation use efficiency as affected by foliar diseases in relation to their vertical position into the canopy in wheat. Field Crops Res. 116:184-195.

Casadesús, J., Kaya, Y., Bort, J., Nachit, M., Araus, J., Amor, S., Ferrazzano, G., Maalouf, F., Maccaferri, M., and Martos, V. 2007. Using vegetation indices derived from conventional digital cameras as selection criteria for wheat breeding in water-limited environments. Ann. Appl. Biol. 150:227236.

Chaerle, L., De Boever, F., Van Montagu, M., and Van Der Straeten, D. 2001. Thermographic visualization of cell death in tobacco and Arabidopsis. Plant Cell Environ. 24:15-25.

Chaerle, L., Hagenbeek, D., De Bruyne, E., Valcke, R., and Van Der Straeten, D. 2004. Thermal and chlorophyll-fluorescence imaging distinguish plant-pathogen interactions at an early stage. Plant Cell Physiol. 45:887-896.

Chaerle, L., Hagenbeek, D., De Bruyne, E., and Van Der Straeten, D. 2007a. Chlorophyll fluorescence imaging for disease-resistance screening of sugar beet. Plant Cell Tiss. Org. 91:97-106.

Chaerle, L., Leinonen, I., Jones, H. G., and Van Der Straeten, D. $2007 \mathrm{~b}$. Monitoring and screening plant populations with combined thermal and chlorophyll fluorescence imaging. J. Exp. Bot. 58:773-784.

Chaerle, L., Pineda, M., Romero-Aranda, R., Van Der Straeten, D., and Barón, M. 2006. Robotized thermal and chlorophyll fluorescence imaging of pepper mild mottle virus infection in Nicotiana benthamiana. Plant Cell Physiol. 47:1323-1336.

Chaerle, L., Van Caeneghem, W., Messens, E., Lambers, H., Van Montagu, M., and Van Der Straeten, D. 1999. Presymptomatic visualization of plant-virus interactions by thermography. Nat. Biotechnol. 17:813-816.

Chaerle, L., and Van Der Straeten, D. 2000. Imaging techniques and the early detection of plant stress. Trends Plant Sci. 5:495-501.

Chaerle, L., and Van Der Straeten, D. 2001. Seeing is believing: Imaging techniques to monitor plant health. Biochim. Biophys. Acta 1519:153-166.

Chelle, M. 2005. Phylloclimate or the climate perceived by individual plant organs: What is it? How to model it? What for? New Phytol. 166:781-790.
Christen, D., Schönmann, S., Jermini, M., Strasser, R. J., and Défago, G. 2007. Characterization and early detection of grapevine (Vitis vinifera) stress responses to esca disease by in situ chlorophyll fluorescence and comparison with drought stress. Environ. Exp. Bot. 60:504-514.

Deery, D., Jimenez-Berni, J., Jones, H., Sirault, X., and Furbank, R. 2014. Proximal remote sensing buggies and potential applications for field-based phenotyping. Agronomy 4:349-379.

Di Giorgio, D., Camoni, L., Mott, K. A., Takemoto, J. Y., and Ballio, A. 1996. Syringopeptins, Pseudomonas syringae pv. syringae phytotoxins, resemble syringomycin in closing stomata. Plant Pathol. 45:564-571.

Durães, F., Gama, E., Magalhães, P., Marriel, I., Casela, C., Oliveira, A., Luchiari, A., Jr., and Shanahan, J. 2002. The usefulness of chlorophyll fluorescence in screening for disease resistance, water stress tolerance, aluminum toxicity tolerance, and $\mathrm{N}$ use efficiency in maize. Pages 356-360 in: Proceedings of the Eastern and Southern Africa Regional Maize Conference, Nairobi, Kenya.

Eyal, Z. 1971. The kinetics of pycnospore liberation in Septoria tritici. Can. J. Bot. 49:1095-1099

Fahlgren, N., Gehan, M. A., and Baxter, I. 2015. Lights, camera, action: Highthroughput plant phenotyping is ready for a close-up. Curr. Opin. Plant Biol. 24:93-99.

Fiorani, F., and Schurr, U. 2013. Future scenarios for plant phenotyping. Annu. Rev. Plant Biol. 64:267-291.

Franke, J., and Menz, G. 2007. Multi-temporal wheat disease detection by multi-spectral remote sensing. Precis. Agric. 8:161-172.

Furbank, R. T., and Tester, M. 2011. Phenomics-technologies to relieve the phenotyping bottleneck. Trends Plant Sci. 16:635-644.

Garcia-Ruiz, F., Sankaran, S., Maja, J. M., Lee, W. S., Rasmussen, J., and Ehsani, R. 2013. Comparison of two aerial imaging platforms for identification of Huanglongbing-infected citrus trees. Comput. Electron. Agric. 91:106-115.

Garin, G., Pradal, C., Andrieu, B., Houles, V., Robert, C., and Fournier, C. 2013. A generic model of interactions between FSPM, foliar pathogens and microclimate. Pages 339-341 in: 7th International Conference on FunctionalStructural Plant Models. R. Sievänen, E. Nikinmaa, C. Godin, A. Lintunen, and P. Nygren, eds., Saariselkä, Finland.

Genc, H., Genc, L., Turhan, H., Smith, S., and Nation, J. 2008. Vegetation indices as indicators of damage by the sunn pest (Hemiptera: Scutelleridae) to field grown wheat. Afr. J. Biotechnol. 7:173-180.

Goggin, F. L., Lorence, A., and Topp, C. N. 2015. Applying high-throughput phenotyping to plant-insect interactions: Picturing more resistant crops. Curr. Opin. Insect Sci. 9:69-76.

Green, J. M., Appel, H., Rehrig, E. M., Harnsomburana, J., Chang, J.-F., Balint-Kurti, P., and Shyu, C.-R. 2012. PhenoPhyte: A flexible affordable method to quantify 2D phenotypes from imagery. Plant Methods 8:45.

Hatfield, P., and Pinter, P. 1993. Remote sensing for crop protection. Crop Prot. 12:403-413

Hillnhütter, C., Sikora, R. A., Oerke, E.-C., and van Dusschoten, D. 2012. Nuclear magnetic resonance: A tool for imaging belowground damage caused by Heterodera schachtii and Rhizoctonia solani on sugar beet. J. Exp. Bot. 63:319-327.

Iori, A., Scala, V., Cesare, D., Pinzari, F., D’Egidio, M., Fanelli, C., Fabbri, A., Reverberi, M., and Serranti, S. 2015. Hyperspectral and molecular analysis of Stagonospora nodorum blotch disease in durum wheat. Eur. J. Plant Pathol. 141:689-702.

Jackson, R. D. 1986. Remote sensing of biotic and abiotic plant stress. Annu. Rev. Phytopathol. 24:265-287.

Julitta, T., Corp, L. A., Rossini, M., Burkart, A., Cogliati, S., Davies, N., Hom, M., Mac Arthur, A., Middleton, E. M., Rascher, U., Schickling, A., and Colombo, R. 2016. Comparison of sun-induced chlorophyll fluorescence estimates obtained from four portable field spectroradiometers. Remote Sens. 8:122.

Klém, K., Rajsnerová, P., Novotná, K., Veselá, B., Mishra, K. B., and Dreiseitl, A. 2015. Development of optical methods for phenotyping of resistance to fungal diseases-A case study with powdery mildew on barley (Blumeria gramins f. sp. hordei). Pages 25-26 in: International Plant and Algal Phenomics Meeting. Prague, Czech Republic.

Kuckenberg, J., Tartachnyk, I., and Noga, G. 2009. Temporal and spatial changes of chlorophyll fluorescence as a basis for early and precise detection of leaf rust and powdery mildew infections in wheat leaves. Precis. Agric. 10:34-44.

Kuska, M., Wahabzada, M., Leucker, M., Dehne, H.-W., Kersting, K., Oerke, E.-C., Steiner, U., and Mahlein, A.-K. 2015. Hyperspectral phenotyping on the microscopic scale: Towards automated characterization of plant-pathogen interactions. Plant Methods 11:28.

Laothawornkitkul, J., Moore, J. P., Taylor, J. E., Possell, M., Gibson, T. D., Hewitt, C. N., and Paul, N. D. 2008. Discrimination of plant volatile signatures by an electronic nose: A potential technology for plant pest and disease monitoring. Environ. Sci. Technol. 42:8433-8439. 
Leufen, G., Noga, G., and Hunsche, M. 2014. Proximal sensing of plantpathogen interactions in spring barley with three fluorescence techniques. Sensors (Basel, Switzerland) 14:11135-11152.

Li, C., Krewer, G. W., Ji, P., Scherm, H., and Kays, S. J. 2010. Gas sensor array for blueberry fruit disease detection and classification. Postharvest Biol. Technol. 55:144-149.

Lindenthal, M., Steiner, U., Dehne, H.-W., and Oerke, E.-C. 2005. Effect of downy mildew development on transpiration of cucumber leaves visualized by digital infrared thermography. Phytopathology 95:233-240.

López-López, M., Calderón, R., González-Dugo, V., Zarco-Tejada, P. J., and Fereres, E. 2016. Early detection and quantification of almond red leaf blotch using high-resolution hyperspectral and thermal imagery. Remote Sens. 8:276.

Mahlein, A.-K. 2016. Plant disease detection by imaging sensors-parallels and specific demands for precision agriculture and plant phenotyping. Plant Dis. 100:241-251.

Mahlein, A.-K., Oerke, E.-C., Steiner, U., and Dehne, H.-W. 2012a. Recent advances in sensing plant diseases for precision crop protection. Eur. J. Plant Pathol. 133:197-209.

Mahlein, A.-K., Steiner, U., Hillnhütter, C., Dehne, H.-W., and Oerke, E.-C. 2012b. Hyperspectral imaging for small-scale analysis of symptoms caused by different sugar beet diseases. Plant Methods 8:3.

Malthus, T. J., and Madeira, A. C. 1993. High resolution spectroradiometry: Spectral reflectance of field bean leaves infected by Botrytis fabae. Remote Sens. Environ. 45:107-116.

Martinelli, F., Scalenghe, R., Davino, S., Panno, S., Scuderi, G., Ruisi, P., Villa, P., Stroppiana, D., Boschetti, M., and Goulart, L. R. 2015. Advanced methods of plant disease detection. A review. Agron. Sustain. Dev. 35:1-25.

Maxwell, K., and Johnson, G. N. 2000. Chlorophyll fluorescence-A practical guide. J. Exp. Bot. 51:659-668.

McDonald, D. W., and Michaels, R. B. 2007. Plant root characterization system. Patent US 7,278,236 B2. Phenotype Screening Corporation, Seymour, TN.

Mewes, T., Franke, J., and Menz, G. 2011. Spectral requirements on airborne hyperspectral remote sensing data for wheat disease detection. Precis. Agric. 12:795-812.

Mirik, M., Ansley, R. J., Price, J. A., Workneh, F., and Rush, C. M. 2013. Remote monitoring of wheat streak mosaic progression using sub-pixel classification of Landsat 5 TM imagery for site specific disease management in winter wheat. Adv. Remote Sens. 2:16-28.

Mirik, M., Jones, D., Price, J., Workneh, F., Ansley, R., and Rush, C. 2011. Satellite remote sensing of wheat infected by Wheat streak mosaic virus. Plant Dis. 95:4-12.

Mirik, M., Michels, G. J., Kassymzhanova-Mirik, S., Elliott, N. C., and Bowling, R. 2006. Hyperspectral spectrometry as a means to differentiate uninfested and infested winter wheat by greenbug (Hemiptera: Aphididae). J. Econ. Entomol. 99:1682-1690.

Mutka, A. M., and Bart, R. S. 2014. Image-based phenotyping of plant disease symptoms. Front. Plant Sci. 5:734.

Narvankar, D., Singh, C., Jayas, D., and White, N. 2009. Assessment of soft X-ray imaging for detection of fungal infection in wheat. Biosystems Eng. 103:49-56.

Niederbacher, B., Winkler, J., and Schnitzler, J. 2015. Volatile organic compounds as non-invasive markers for plant phenotyping. J. Exp. Bot. 66: 5403-5416.

Nilsson, H.-E. 1995a. Remote sensing and image analysis in plant pathology. Can. J. Plant Pathol. 17:154-166.

Nilsson, H.-E. 1995b. Remote sensing and image analysis in plant pathology. Annu. Rev. Phytopathol. 33:489-528.

Oerke, E., Steiner, U., Dehne, H., and Lindenthal, M. 2006. Thermal imaging of cucumber leaves affected by downy mildew and environmental conditions. J. Exp. Bot. 57:2121-2132.

Oerke, E.-C., Fröhling, P., and Steiner, U. 2011. Thermographic assessment of scab disease on apple leaves. Precis. Agric. 12:699-715.

Olmstead, J. W., Lang, G. A., and Grove, G. G. 2001. Assessment of severity of powdery mildew infection of sweet cherry leaves by digital image analysis. HortScience 36:107-111.

Paveley, N. 1999. Integrating Septoria risk variables. Pages 230-250 in: Septoria on Cereals: A Study of Pathosystems. CABI Publishers, Wallingford, UK.

Pielaat, A., Van Den Bosch, F., Fitt, B. D., and Jeger, M. 2002. Simulation of vertical spread of plant diseases in a crop canopy by stem extension and splash dispersal. Ecol. Modell. 151:195-212.

Pridmore, T. P., French, A. P., and Pound, M. P. 2012. What lies beneath: Underlying assumptions in bioimage analysis. Trends Plant Sci. 17:688-692.
Raesch, A. R., Muller, O., Pieruschka, R., and Rascher, U. 2014. Field observations with laser-induced fluorescence transient (LIFT) method in barley and sugar beet. Agriculture 4:159-169.

Rolfe, S. A., and Scholes, J. D. 2010. Chlorophyll fluorescence imaging of plant-pathogen interactions. Protoplasma 247:163-175.

Rousseau, C., Belin, E., Bove, E., Rousseau, D., Fabre, F., Berruyer, R., Guillaumès, J., Manceau, C., Jacques, M.-A., and Boureau, T. 2013. High throughput quantitative phenotyping of plant resistance using chlorophyll fluorescence image analysis. Plant Methods 9:17.

Rousseau, C., Hunault, G., Gaillard, S., Bourbeillon, J., Montiel, G., Simier, P., Campion, C., Jacques, M.-A., Belin, E., and Boureau, T. 2015. Phenoplant: A web resource for the exploration of large chlorophyll fluorescence image datasets. Plant Methods 11:24.

Rumpf, T., Mahlein, A.-K., Steiner, U., Oerke, E.-C., Dehne, H.-W., and Plümer, L. 2010. Early detection and classification of plant diseases with support vector machines based on hyperspectral reflectance. Comput. Electron. Agric. 74:91-99.

Sakdinawat, A., and Attwood, D. 2010. Nanoscale X-ray imaging. Nat. Photonics 4:840-848.

Sankaran, S., Maja, J. M., Buchanon, S., and Ehsani, R. 2013. Huanglongbing (citrus greening) detection using visible, near infrared and thermal imaging techniques. Sensors (Basel, Switzerland) 13:2117-2130.

Sankaran, S., Mishra, A., Ehsani, R., and Davis, C. 2010. A review of advanced techniques for detecting plant diseases. Comput. Electron. Agric. $72: 1-13$.

Schmittgen, S., Metzner, R., Van Dusschoten, D., Jansen, M., Fiorani, F., Jahnke, S., Rascher, U., and Schurr, U. 2015. Magnetic resonance imaging of sugar beet taproots in soil reveals growth reduction and morphological changes during foliar Cercospora beticola infestation. J. Exp. Bot. 66: 5543-5553.

Scholes, J. D., and Rolfe, S. A. 2009. Chlorophyll fluorescence imaging as tool for understanding the impact of fungal diseases on plant performance: A phenomics perspective. Funct. Plant Biol. 36:880-892.

Simko, I. 2013. Marker-assisted selection for disease resistance in lettuce. Pages 267-289 in: Translational Genomics for Crop Breeding. Volume I: Biotic Stresses. R. K. Varshney and R. Tuberosa, eds. Wiley-Blackwell Publishers, Hoboken, NJ.

Simko, I., Jimenez-Berni, J. A., and Furbank, R. T. 2015. Detection of decay in fresh-cut lettuce using hyperspectral imaging and chlorophyll fluorescence imaging. Postharvest Biol. Technol. 106:44-52.

Simko, I., Rauscher, G., Sideman, R. G., McCreight, J. D., and Hayes, R. J. 2014. Evaluation and QTL mapping of resistance to powdery mildew in lettuce. Plant Pathol. 63:344-353.

Sirault, X., Fripp, J., Paproki, A., Kuffner, P., Nguyen, C., Li, R., Daily, H., Guo, J., and Furbank, R. 2013. PlantScan: A three-dimensional phenotyping platform for capturing the structural dynamic of plant development and growth. Pages 9-14 in: Proceedings of the 7th International Conference on Functional-Structural Plant Models. R. Sievänen, E. Nikinmaa, C. Godin, A. Lintunen, and P. Nygren, eds. Saariselkä, Finland.

Steiner, U., Bürling, K., and Oerke, E.-C. 2008. Sensorik für einen präzisierten. Pflanzenschutz. Gesunde Pflanzen 60:131-141.

Taubenhaus, J., Ezekiel, W., and Neblette, C. 1929. Airplane photography in the study of cotton root rot. Phytopathology 19:1025-1029.

Waggoner, P. E., and Berger, R. D. 1987. Defoliation, disease, and growth. Phytopathology 77:393-398.

Walcott, R., McGee, D., and Misra, M. 1998. Detection of asymptomatic fungal infections of soybean seeds by ultrasound analysis. Plant Dis. 82: 584-589.

White, J. W., Andrade-Sanchez, P., Gore, M. A., Bronson, K. F., Coffelt, T. A., Conley, M. M., Feldmann, K. A., French, A. N., Heun, J. T., and Hunsaker, D. J. 2012. Field-based phenomics for plant genetics research. Field Crops Res. 133:101-112.

Yang, C., Everitt, J. H., and Fernandez, C. J. 2010. Comparison of airborne multispectral and hyperspectral imagery for mapping cotton root rot. Biosystems Eng. 107:131-139.

Young, N. 1996. QTL mapping and quantitative disease resistance in plants. Annu. Rev. Phytopathol. 34:479-501.

Zhou, B., Elazab, A., Bort, J., Vergara, O., Serret, M., and Araus, J. 2015. Low-cost assessment of wheat resistance to yellow rust through conventional RGB images. Comput. Electron. Agric. 116:20-29.

Zhou, J., Spallek, T., Faulkner, C., and Robatzek, S. 2012. CalloseMeasurer: A novel software solution to measure callose deposition and recognize spreading callose patterns. Plant Methods 8:49. 